\title{
Sanctity
}

\author{
All life is here.
}

\section{Heather Bradshaw}

I remember how Pieto's voice and my footfalls echoed slightly around his quiet words as I walked beside him to the vaults.

"Of course, the calculations were quite troublesome. Generations suffered in exploration and verification of the embodiments."

I felt the weight of responsibility press at my shoulders. My duty was a grave thing indeed. "We have recorded every possible combination, even those that could not live and those that could not be embodied in mathematical completeness. And we have recorded, as far as we can know, all those that have been lived ... but you have studied in the Archives of Narrative."

I nodded; they were a work of the utmost dignity. Historians and archaeologists had spent generations building this memorial. Slowly they had pieced together what could be known of the ages before Awareness. Yet the archives epitomized incompleteness.

"But of those not yet lived we despaired. Ah, how we despaired! So many, so many cut short before reaching life, through the exigencies of life itself, primitivity. And then by the ignorance that must be forgiven. You remember, of course, how once there were such crowds that people chose ... chose not to let their buds flower."

Well, not remember exactly. But I nodded again. It was astonishing that such a small proportion of the possibilities had been actualized in all the history of this life.

After our devotions at the crucifix I unlocked the great doors and Pieto moved over to the simulation boards. He did not even look at the airlock leading to the repository.

"The answer to our despair," he whispered as his hands flew over the ebony surfaces of the boards, waking the light beneath.

I recall the intensity of these, his last words, each time I light the boards myself. Moments after he spoke them we took our final parting and he transcended into a simulation of his choosing. I know not which, and I have never found a sign of him in any I have since visited. I would like to believe he lives on still within their ethereality, but I knew him well enough to realize that he went there to die and be mourned and buried, as was the wont of his kind. So he is gone. And I am left with the care of all he held dear.

There have been developments despite the previous running of the simulations. Some groups and forms I have split out and restarted in their own universes, where they have a better chance of developing their potential. Of course, the main cluster of mixed simulations I have kept running, mutants to another universe to prevent a crisis of inequality.) And one or two universes I have closed, for no new, previously unexperienced combinations had appeared in over a thousand generations. Resources did not permit continuation of already recorded combinations, despite their subtly different narratives. I hope I will be forgiven for this. They could be restarted with ease, given more resources.

With the closing of the human nanosupported facilities here, the removal of the final avatar and the subsequent death of the body it represented: Pieto the Wise,

the drain on our limited resources was much reduced. I myself take up but a fraction of the protection a human body would require, and my energy needs are negligible in comparison with those of the simulations and the repository. Yet energy and time are limited.

In simulation I have experienced the emotions of a human being, and borne their individual and collective burdens to the extent my designed-in limits permit me. I feel now, to some very small degree, that my distress is analogous to that which a human might have felt in this situation. This is why now I begin to understand why Pieto felt such attachment to the simulations, and indeed such temptation to enter their worlds of promise and hope. But I cannot take that escape now, if ever, for I was created to avoid that temptation. And in my distress I have turned to a strange and very human recourse, to keep a record of my own path and progress, a record that will at least be as safe and protected here as anything else I value. Here I record what I must face, unfit as I am for the purpose, ignorant of assistance for which I do not dare hope. This is my duty that my will must enforce. Over the years to come I must struggle to preserve the only life I have known: the complete record and exemplification in simulation of the combinations of the DNA of the human species. I must preserve the Sanctity of Life.

Heather Bradshaw is studying for her PhD in bioethics in Bristol. Her earliest memory of creative writing is describing a monsoon storm at midnight using a blunt pencil on a construction site in Pakistan, aged six. 